\title{
O Processo de Inclusão no Ensino Regular
}

\author{
Maria das Dores Matos ${ }^{1}$
}

\begin{abstract}
Resumo: Este artigo objetiva analisa como se dá o processo de inclusão no ensino regular. Inicialmente, entendemos por inclusão a capacidade de reconhecer o outro, e assim ter o privilégio de conviver e compartilhar com pessoas diferentes de nós, sem exceção. A inclusão escolar traz para alunos e professores a experiência da diferença, possibilitando aos que são descriminados pela deficiência, pela classe social ou pela cor que por direito ocupam seu espaço na sociedade vencer os preconceitos. A diversidade foi entendida como uma inovação na área de educação especial, mas, gradualmente, passou a ser compreendida como uma tentativa de oferecer educação de qualidade para todo (a)s. O método de pesquisa utilizado foi o bibliográfico, desenvolvido a partir de material já elaborado. A revisão da literatura analisa o histórico e contextualização da inclusão escolar no Brasil, a legislação a favor da inclusão, a postura da escola e a adaptação curricular, o processo de inclusão e a aprendizagem, escola e família no processo de inclusão. Os resultados e discussões revelam que a concepção de inclusão do aluno com necessidades educacionais especiais no ensino regular favorece o encontro das possibilidades e capacidades da verdadeira inclusão. Portanto, do que se chama de conjunto central de valores deve valer a liberdade, a tolerância e a sabedoria de conviver com o diferente.
\end{abstract}

Palavras-chave: Processo Inclusivo; Ensino Aprendizagem; Ensino regular.

\section{The Process of Inclusion in mainstream Education}

\begin{abstract}
This article aims to analyze how is the process of inclusion in mainstream education. Initially, we understand by including the ability to recognize the other, and thus have the privilege to live and share with different people of us, without exception. School inclusion brings students and teachers to experience the difference, allowing those who are discriminated by disability, social class or the right color that occupy their space in society overcome prejudices. Diversity was understood as an innovation in the field of special education, but gradually began to be understood as an attempt to provide quality education for all (a) s. The research method used was a literature developed from already prepared material. The literature review examines the history and context of school inclusion in Brazil, in favor of including legislation, school posture and curriculum adaptation, the process of inclusion and learning, school and family in the inclusion process. The results and discussions show that the concept of inclusion of students with special educational needs in mainstream education favors the meeting of the possibilities and capabilities of true inclusion. Therefore, the so-called core set of values must be true freedom, tolerance and wisdom to live with the other.
\end{abstract}

Keywords: Inclusive Process; Education; Regular education.

Keywords: Marfan syndrome, FBN1, Diagnosis, Treatment, TGF- $\beta$.

\footnotetext{
${ }^{1}$ Mestranda em Ciências da Educação pela ANNE SULLIVAN- UNIVERSITY -Mestrado Internacional em Educação.
} 
Id on Line Revista Multidisciplinar e de Psicologia

Id on Line Multidisciplinary and Psycology Journal

\section{Introdução}

Este artigo discute a importância do processo de inclusão no ensino regular. O interesse pela temática parte do pressuposto de que através dessa prática possa-se oferecer oportunidades a todos para compensar as desigualdades existentes e formar "pessoas iguais" de modo a alcançarmos uma educação de qualidade para todos (as), centrada no respeito e valorização das diferenças.

$\mathrm{Na}$ tentativa de contextualizar brevemente o objeto de estudo foi necessário reconhecer como o processo de inclusão no ensino regular pode contribuir para que de fato os alunos com necessidades educacionais especiais possam ser inseridos no processo de ensino tendo seu desenvolvimento intelectual e subjetivo desenvolvido numa perspectiva funcional.

No processo de inclusão é preciso reconhecer as diferenças individuais, sociais e culturais a partir da ação educacional orientada, que permite a adequação aos diferentes processos de ensino-aprendizagem às diferentes situações.

Conhecer o conceito de diversidade é inerente é inerente à educação inclusiva, ao mesmo tempo em que cada educando possui uma maneira própria e específica de absorver experiências e adquirir conhecimentos, embora todas as crianças apresentem necessidades básicas comuns de aprendizagem, os quais são expressas no histórico escolar e obedecem diretrizes gerais de desempenho acadêmico.

Após uma breve contextualização e delimitação do objeto desse estudo, o próximo passo é fazer uma problematização que vai dar cabo a construção do problema da pesquisa.

Nesse sentido formulou-se as seguintes problemáticas: Será que a inclusão do aluno no ensino regular está proporcionando a formação que assegura o exercício da cidadania? A postura da escola e a adaptação curricular na ação pedagógica está em pleno funcionamento numa perspectiva inclusiva considerando a diversidade presente em sala de aula? O processo de inclusão está visando a aprendizagem tendo a família e escola como parceiros indispensáveis nesse processo?

Tendo em vista as problemáticas apresentadas acima elaborou-se o seguinte problema de pesquisa: Como acontece o processo de inclusão no ensino regular. Na perspectiva de facilitar a solução desse problema, formulou-se a hipótese de pesquisa segundo a qual a prática 
inclusiva cotidiana na instituição de ensino abordada na literatura esta sendo cumprida para o pleno desenvolvimento do aluno.

Considerando as delimitações do estudo definiu-se como objetivo geral da pesquisa compreender como o processo de inclusão no ensino regular acontece, contribuindo para o debate sobre a sua inclusão regular na prática pedagógica dos educadores desta modalidade de ensino. Como objetivos específicos, delineou-se os seguintes: a) Verificar de forma sistemática o que é e como acontece a inclusão do aluno com necessidades educacionais na escola de ensino regular; b) Identificar na literatura o contexto histórico e a legislação da inclusão escolar no Brasil ; c) Propor alternativas metodológicas para que a escola e a família possam se ajudar em prol do pleno desenvolvimento do aluno.

Esta pesquisa surgiu da necessidade em atender as exigências acadêmicas e da curiosidade sobre o tema, assim como a expectativa de evidenciar as práticas teóricas objetivando conhecer de que forma se dá o processo de inclusão no ensino regular, respeitando seus tempos e direitos.

Do ponto vista dos procedimentos metodológicos, esta pesquisa se constitui em um estudo de caráter bibliográfico na qual foram utilizadas diversas técnicas e instrumentos para possibilitar a solução do problema.

\section{O Que é Inclusão?}

Inclusão é a nossa capacidade de entender e reconhecer o outro, e assim ter o privilégio de conviver e partilhar com as pessoas diferentes de nós é inclusão. A educação inclusiva deve acolher todas as pessoas sem exceção. É para o estudante com deficiência para o estudante com deficiência física, para os que têm comprometimento mental, para os superdotados, para todas as crianças que são discriminadas por algum outro motivo.

\footnotetext{
A educação inclusiva pode ser definida como a prática da inclusão de todos independente de seu talento, deficiência, origem socioeconômica ou cultural em escolas e salas de aula provedoras, onde as necessidades desses alunos sejam satisfeitas. A inclusão requer mudança de paradigmas, compreender e aceitar o outro em suas diferenças, abrir horizontes, desejar e realizar mudanças profundas nas práticas educacionais, proporcionando um ambiente que favoreça a aprendizagem. VANIN, Luciene de Souza. Educação Inclusiva: Igualdade na Diferença. Porto Alegre UFPB, (2005, p.06)
} 
Inclusão escolar é acolher todas as pessoas, sem exceção, no sistema de ensino, independentemente de cor, classe social e condições físicas e psicológicas. O termo é associado mais comumente à inclusão educacional de pessoas com deficiência física e mental.

Neste contexto, a escola deve ser o reflexo da vida do lado de fora, sendo o grande ganho para todos a experiência de viver a diferença. Se os estudantes não passam por isso na infância futuramente terão muitas dificuldades em conviver com o preconceito.

A inclusão é mais do que rampas e banheiros adaptados, mas toda uma equipe escolar preparada para dar subsidia através das práticas pedagógicas que na maioria das vezes precisam se revistas. É importante que os professores deem oportunidade de liberdade para que cada aluno aprenda a seu modo, ou seja, de acordo com suas limitações.

\section{Contexto Histórico da Inclusão Escolar no Brasil}

A luta contra todas as formas de discriminação que impediam o exercício da cidadania das pessoas com deficiência surgiu a partir de meados do século XX, com a intensificação dos movimentos sociais, emergiu, em nível mundial, a defesa de uma sociedade realmente inclusiva.

É nesse período histórico, que são fortalecidas as críticas às práticas de categorização e segregação de estudantes encaminhados para ambientes especiais, que conduzem, também, ao questionamento dos modelos homogeneizadores de ensino e de aprendizagem, geradores de exclusão nos espaços escolares.

Em 1990, Na busca de tentar diminuir a exclusão das pessoas com deficiência de forma a enfrentar esse desafio, foram construídos projetos capazes de superar os processos históricos de exclusão, a Conferência Mundial de Educação para Todos chama a atenção dos países para os altos índices de crianças, adolescentes e jovens sem escolarização, tendo como objetivo promover as transformações nos sistemas de ensino para assegurar o acesso e a permanência de todos na escola. 
Como exemplo, expõe-se aqui a declaração mundial para todos firmada em Jomvitien na Tailândia em 1990 na conferencia Mundial Sobre necessidades Educacionais especiais: acesso e qualidade.

Essa declaração enquadra-se na ação sobre necessidades Educativas Especiais foi adaptado pelo Congresso Mundial sobre Necessidades Educativas Especiais, organizado pelo Governo de Espanha em colaboração com a UNESCO e realizou-se em Salamanca, de 7 a 10 de Junho de 1994.

Seu objetivo maior foi estabelecer uma política que orientassem os governos, organizações internacionais, organizações de apoio nacionais, organizações não governamentais e outros organismos, através da implementação da Declaração de Salamanca sobre Princípios, Política e Prática na área das Necessidades Educativas Especiais. O Enquadramento da Ação inspira-se na experiência a nível nacional dos países participantes, assim como nas resoluções, recomendações e publicações das Nações Unidas e de outras organizações inter governamentais, especialmente nas Normas sobre Igualdade de Oportunidades para Pessoas com Deficiência. Baseia-se, igualmente, nas propostas, diretrizes e recomendações formuladas nos cinco seminários regionais, preparatórios deste Congresso.

O direito de todas as crianças à educação está proclamado na Declaração Universal dos Direitos Humanos e foi reafirmado com veemência pela Declaração sobre Educação para Todos.

Todas as pessoas com deficiência têm o direito de expressar os seus desejos em relação à sua educação. Os pais têm o direito inerente de ser consultados sobre a forma de educação que melhor se adapte às necessidades, circunstâncias e aspirações dos seus filhos. (UNESCO, Declaração de Salamanca e Enquadramento da Ação, 1994).

A educação de alunos com necessidades educativas especiais incorpora os princípios já comprovados de uma pedagogia saudável da qual todas as crianças podem beneficiar, assumindo que as diferenças humanas são normais e que a aprendizagem deve será adaptada às necessidades da criança, em vez de ser esta a ter de se adaptar a concepções predeterminadas, relativamente ao ritmo e à natureza do processo educativo.

Uma pedagogia centrada na criança é benéfica para todos os alunos e, como consequência, para a sociedade em geral, pois a experiência tem demonstrado que esta pedagogia pode reduzir substancialmente as desistências e as repetições e garantir um êxito 
escolar médio mais elevado. Uma pedagogia deste tipo pode também ajudar a evitar o desperdício de recursos e a destruição de esperanças, o que, muito frequentemente, acontece como consequência do baixo nível do ensino "uma medida serve para todos" relativa à educação.

As escolas centradas na criança são, assim, a base de construção para uma sociedade orientada para as pessoas, respeitando as diferenças de todos os seres humanos. Este Enquadramento da Ação compreende as seguintes seções:

I. Novas concepções sobre educação de alunos com necessidades educativas especiais

II. Diretrizes para a ação a nível nacional:

A. Política e organização.

B. Fatores Escolares.

C. Recrutamento e treino de pessoal docente.

D. Serviços externos de apoio.

E. Áreas prioritárias.

F. Perspectivas comunitárias.

G. Recursos necessários.

III. Diretrizes da ação a nível regional e internacional.

\section{A Legislação em Favor da Inclusão}

A Educação Especial, como modalidade de educação escolar, organiza-se de modo a considerar uma aproximação sucessiva dos pressupostos e da prática pedagógica social da educação inclusiva, a fim de cumprir os seguintes dispositivos legais e políticos filosóficos que embasam a Política de Educação Inclusiva no Brasil:

A Constituição da República Federativa do Brasil estabelece que:

Promover o bem de todos, sem preconceitos de origem, raça, sexo, cor, idade e quaisquer outras formas de discriminação (art. $3^{\circ}$ inciso IV). Define, ainda, no artigo 205, a educação como um direito de todos, garantindo o pleno desenvolvimento da pessoa, o exercício da cidadania e a qualificação para o trabalho. No artigo 206, inciso I, estabelece a "igualdade de condições de acesso e permanência na escola" como um dos princípios para o ensino e garante como dever do Estado, a oferta do atendimento educacional especializado, preferencialmente na rede regular de ensino (art. 208). 
O Estatuto da Criança e do Adolescente - Lei no. 8.069/90 . Em seu artigo 55 reforça os dispositivos legais supracitados ao determinar que "os pais ou responsáveis têm a obrigação de matricular seus filhos ou pupilos na rede regular de ensino".

A Lei de Diretrizes e Bases da Educação Nacional - Lei no 9.394/96 No artigo 59 preconiza que os sistemas de ensino devem assegurar aos alunos o currículo, os métodos, recursos e organização específicos para atender às suas necessidades; assegura a terminalidade específica àqueles que não atingiram o nível exigido para a conclusão do ensino fundamental em virtude de suas deficiências e; a aceleração de estudos aos superdotados para conclusão do programa escolar. Também define, dentre as normas para a organização da educação básica, a "possibilidade de avanço nos cursos e nas séries mediante verificação do aprendizado" (art. 24, inciso V) e "(...) oportunidades educacionais apropriadas, consideradas as características do alunado, seus interesses, condições de vida e de trabalho, mediante cursos e exames" (art. 37). Em seu trecho mais controverso (art. 58 e seguintes), diz que "o atendimento educacional especializado será feito em classes, escolas ou serviços especializados, sempre que, em função das condições específicas dos alunos, não for possível a sua integração nas classes comuns do ensino regular".

\section{A Escola e a Adaptação Curricular}

Para entendermos melhor este segundo capítulo vamos começar esclarecendo o que é adaptação curricular. Na LDB 9394/1996 (Lei Diretrizes e Bases da Educação) e no Plano Nacional de Educação determinam que a escola se mobilize para estruturar um conjunto de ações e providenciar recursos necessários que garantam o acesso e a permanência de todos os alunos, promovendo um ensino que respeite as especificidades da aprendizagem de cada um.

Nesse sentido a pedagogia inclusiva já é uma realidade a partir da opção da descentralização do ensino, assumida na Constituição de 1988. Para que de fato a adaptação curricular aconteça é necessário que o projeto pedagógico da escola e o planejamento de ensino considerem os objetivos educacionais e estratégias didático-pedagógicas que garantam acessibilidade de todos os alunos na rede escolar. 
Id on Line Revista Multidisciplinar e de Psicologia

Id on Line Multidisciplinary and Psycology Journal

A proposta pedagógica numa perspectiva inclusiva deverá considerar que a diversidade presente em sala de aula, nas diferentes formas de aprender enriquece o processo educacional. Nela o professor educador, assume grande responsabilidade na superação de barreiras de atitudes discriminatórias em relação às diferenças dentro da escola. No seu estabelecimento maneiras diversificadas de organizar o tempo e o espaço pedagógicos precisam ser previstos para o sucesso escolar, respeitando os estilos e ritmos de aprendizagem, planejando estratégias e recursos utilizados, adequando-os às necessidades dos alunos.

Assim, o professor tem que conhecer o processo de aprendizagem dos alunos, entender como cada um aprende os conhecimentos historicamente acumulados apresentados no espaço escolar. Segundo Perrenoud (2001), grande parte das estratégias de ensino utilizadas pelo professor deve ser adaptada às características dos alunos, à composição da classe e a história das relações entre os educandos e entre eles e o professor.

Desse modo, fica clara a importância da realização de adaptações curriculares para a inclusão do aluno com necessidades educacionais especiais, principalmente para àqueles que apresentam deficiência mental.

Segundo os Parâmetros, Curriculares Nacionais - PCN as adaptações Curriculares em ação, elaborado pela Secretaria de Educação Especial, do Ministério da Educação, publicado originalmente em 1999 e reeditado em 2002, as adaptações curriculares devem ser entendidas como um processo a ser realizado em três níveis:

- No projeto político pedagógico da escola, por meio do qual é possível identificar e analisar as dificuldades enfrentadas pela escola assim como estabelecer objetivos e metas comuns aos gestores, professores, funcionários da escola, familiares e alunos;

- No currículo desenvolvido em sala de aula;

- No nível individual, por meio da elaboração e implementação do Programa Educacional Individualizado (PEI).

O professor, então, na postura de mediador da construção de conhecimentos, deve se preocupar com quem aprende como aprende, com o porquê de estar trabalhando determinado conhecimento e, sobretudo, com a reflexão constante sobre o que está sendo discutido, dando abertura para a manifestação dos posicionamentos e ideias, contrário a sua ou não (LEITE, 2003). 
Id on Line Revista Multidisciplinar e de Psicologia

Id on Line Multidisciplinary and Psycology Journal

$\mathrm{Na}$ proposta educacional inclusiva o currículo deve ser pautado também da ideia da diferença, e não é o aluno que se ajusta, se adapta as condições de ensino, mas a leitura do movimento da inclusão educacional é justamente contrária, é a equipe escolar que tem que prover as mudanças necessárias para que o aluno consiga acessar o currículo (Aranha, 2003).

\section{O processo de Inclusão e a Aprendizagem}

Todos os alunos em determinado momento de sua vida escolar, podem apresentar necessidades educacionais, e seus professores, em geral, conhecem diferentes estratégias para dar respostas a elas. No entanto existem necessidades educacionais que requerem da escola, uma serie de recursos e apoios de caráter mais especializado, que proporcionem ao aluno meios para que de fato possa realizar suas atividades, mesmo com suas impossibilidades e limitações.

A existência de dificuldades individuais geradas por limitações de ordem neurológica e intelectual, inerentes ao processo de aprendizagem, exige mediações especiais para que o aprendiz cheque a um grau de conhecimento satisfatório. Essa limitação afeta de maneira acentuada a sua capacidade para resolver problemas frente às exigências a que são submetidos no seu dia-a-dia. Cabe à escola, porém, dispor de recursos e procedimentos não uniformes para que os alunos tenham possibilidades de caminhar além de seus limites.

\footnotetext{
O movimento pela inclusão abrange várias ações como, cultural, pedagógica, social e política, buscando o direito de todos os alunos poderem aprender, participar e estar juntos, sem nenhum tipo de exclusão. A educação inclusiva faz parte de um paradigma educacional que se fundamenta na concepção dos direitos humanos, que luta pela igualdade, e que avança em relação ao ideal de justiça nas circunstâncias que revelam exclusão dentro ou fora da instituição escolar. POLÍTICA NACIONAL DE EDUCAÇÃO ESPECIAL NA PERSPECTIVA DA EDUCAÇÃO INCLUSIVA, 2008 Apud (Tédde em: Crianças Com Deficiência Intelectual: A Aprendizagem e a Inclusão. Centro Universitário Salesiano de São Paulo, 2012, p 22).
}

No século XIX médico Jean Itard (1774-1838) considerado o primeiro teórico de Educação Especial com o menino Victor de Aveyron, conhecido como "menino selvagem". Itard se baseava na teoria empirista do conhecimento. Contudo, a importância atribuída aos fatores biológicos em detrimento dos fatores socioambientais perdurou até os anos cinquenta, quando a noção de "irrecuperabilidade e constitucionalidade da condição de deficiente mental" começou a inserir em suas proposições aspectos sócioeducacionais. 
Como se falou anteriormente a existência de dificuldades individuais geradas por limitações, inerentes ao próprio indivíduo, que exigem mediações especiais para sua constituição como na condição de aprendizes. Essa limitação afeta de maneira acentuada a sua capacidade para resolver problemas frente às exigências a que são submetidos no seu dia a dia.

Nesse sentido é importante que o professor oportunize ao aluno situações coletivas de afetividade ressaltando a importância de que entre as pessoas não deve haver rotulação pelo fato de apresentarem um comportamento adaptativo prejudicado, pois existem vários outros fatores que podem levar a um desenvolvimento maturacional lento como um processo escolar sem qualidade ou um ajustamento social e ocupacional inadequado.

\section{Escola e Família: Parceiros Indispensáveis no Processo de Inclusão.}

As considerações acerca desse tópico visa explicar a importância da participação da família aliada à escola como forma de somar esforços objetivando o sucesso do aluno no processo educacional. Há muitas definições para a palavra família, a resposta para seu significado pode ser um grupo de pessoas descendentes a partir de um ancestral comum, é quando se acolhe um indivíduo e este é considerado como filho. Pode considerar que na família sempre há laços os quais permitem a respeitabilidade dos membros, que de acordo com o relacionamento entre eles perdura uma vida inteira. Podemos dizer ainda que família é um conjunto de exigências que organiza a interação da convivência de pessoas de maneira harmoniosa.

Por outro lado a definição para a palavra escola na realidade, esta na instituição, alguns pais a consideram como se fosse a extensão da família, mas não pela sua importância e função social mas por transferirem a responsabilidade que é sua de fato, para os professores. Estes, muitas vezes agem de forma equivocada, quando ficam presos aos conteúdos que dizem respeito apenas à sua disciplina, Baldoino citado por Enguita, (1990, 152 apud SACRISTÁN E GÓMEZ) diz que: [...] a escola é uma trama de relações sociais materiais que organizam a experiência cotidiana e pessoal do aluno/a com a mesma força ou mais que as relações de produção podem organizar as do operário na oficina ou as do pequeno produtor no mercado. 
Id on Line Revista Multidisciplinar e de Psicologia

Id on Line Multidisciplinary and Psycology Journal

Sem dúvidas a família tem que estar intrinsecamente ligada à escola de modo que tenha o acompanhamento real sobre como está indo o desenvolvimento da sua prole para que de fato faça parte do processo educativo.

Estatuto da Criança e do Adolescente (Lei 8069/90), nos artigos $4^{\circ}$ e 55 ; Lei de Diretrizes e Bases da Educação (Lei 9394/96), artigos 1º $2^{\circ}, 6^{\circ}$ e 12; Plano Nacional de Educação (aprovado pela Lei n ${ }^{\circ} 10172 / 2007$ ), que define como uma de suas diretrizes a implantação de conselhos escolares e outras formas de participação da comunidade escolar (composta também pela família) e local na melhoria do funcionamento das instituições de educação e no enriquecimento das oportunidades educativas e dos recursos pedagógicos. Citamos ainda, a Política Nacional de Educação Especial, que tem como uma de suas diretrizes gerais: adotar mecanismos que oportunizem a participação efetiva da família no (SILVA, 2008 p. 03).

A parceria escola/família é fundamental para que se construa uma educação de qualidade. Nos dias atuais surge a necessidade das duas instituições se entenderem melhor e começarem um novo processo educacional valorizando os princípios de cada uma. O capítulo seguinte abordará algumas possíveis propostas que poderão ser adotadas pelas escolas e pelas famílias durante o ano letivo ou talvez até após o período das aulas. Segundo Almeida (2008, p. 10) Ocorre envolvimento da família nas práticas inclusivas da escola quando:

\begin{abstract}
Entre a escola e a família há um sistema de comunicação com o qual ambas as partes concordam. Os pais participam nas reuniões da equipe escolar para planejar, adaptar o currículo e compartilhar sucessos. As famílias são reconhecidas pela escola como parceiros plenos junto à equipe escolar. As prioridades da família são utilizadas como uma base para o preenchimento do Plano Individualizado de Educação (PIE) do seu filho, base essa que será completada com partes do conteúdo curricular. Os pais recebem todas as informações relevantes (os direitos dos pais, práticas educativas atuais, planejamento centrado-na-pessoa, notícias da escola etc.). Os pais recebem ou têm acesso a treinamento relevante. Os pais são incluídos no treinamento com a equipe escolar. Os pais recebem informações sobre os serviços de apoio à família. Existem à disposição de membros das famílias serviços de apoio na própria escola (aconselhamento e grupos de apoio, informações sobre deficiências etc.). Os pais são estimulados a participarem em todos os aspectos operacionais da escola (voluntários para salas de aula, membros do conselho da escola, membros da Associação de Pais e Mestres, treinadores etc.). Existem recursos para as necessidades especiais da família (reuniões após o horário comercial, intérpretes da língua de sinais, materiais traduzidos etc.). A escola respeita a cultura e a etnicidade das famílias e reconhece o impacto desses aspectos sobre as práticas educativas.
\end{abstract}

Diante do exposto, percebe-se que a Família e escola jamais devem ficar indiferentes perante a gravidade dos problemas sociais que os cidadãos, principalmente os jovens, 
enfrentam. Por saber que a estrutura desses indivíduos ainda é frágil para ter discernimento suficiente no ato da escolha de qual atitude tomar.

O incentivo dos pais é de grande importância para que ocorra de fato a inclusão dessas pessoas com necessidades educacionais especiais, pois se os próprios pais os acharem incapazes, e não se importarem com os seus direitos em ter uma vida melhor, com qualidade, sem restrições, estarão privando-os de uma série de experiências importantes para seu desenvolvimento.

\section{Considerações Finais}

Ao produzir este artigo percebeu-se que o processo de inclusão no ensino regular constitui uma situação real dentro da instituição escolar. Diante disso faz-se necessário que todos os envolvidos no processo de ensino sejam leitores e pesquisadores sobre está temática de forma a aderir totalmente a inclusão de pessoas com necessidades educacionais na escola de ensino regular.

É importante ressaltar que um grande caminho foi percorrido entre a inclusão e a exclusão escolar e social. Até bem pouco tempo a teoria e a prática dominante definiam a organização de escola e de classes especiais separando essa população dos demais alunos. Nem sempre mais em muitos casos a escola especial desenvolvia-se em regime residencial e, consequentemente, a criança, o jovem ou adolescente eram afastados da família e da sociedade, sendo este posicionamento uma grade contribuição para o preconceito.

Ao finalizar esta pesquisa foi possível reconhecer que para a educação inclusiva acontecer na prática é necessária a qualidade, eficiência e competência de todos os envolvidos no processo educacional, bem como a disponibilidade de recursos e oferecimento de boa estrutura escolar ofertada pelas políticas públicas, pois a educação inclusiva necessita do seu cumprimento de acordo com a qualidade que a legislação brasileira oferece. 
Id on Line Revista Multidisciplinar e de Psicologia

Id on Line Multidisciplinary and Psycology Journal

\section{Referências}

BRASIL. Conferências Nacionais de Direitos Humanos - Câmara dos Deputados/CDHM.Brasília: CORDE, (1996).

. Conselho Nacional de Educação. Câmara de Educação Básica. Resolução no 2, de11 de fevereiro de 2001. Institui Diretrizes Nacionais para a Educação Especial na Educação Básica. Disponível em: http://www.portal.mec.gov.br/seesp. Acesso em: abr. 2006.

\section{Declaração de Salamanca e Linha de Ação sobre necessidades Educativas}

Especiais. Brasília: Corde. 1994.

SEESP, 2001.

Diretrizes Nacionais para Educação Especial na Educação Básica. MEC

Estatuto da Criança e do Adolescente: Lei nº. 8.069/1990. Brasília: 1990.

Lei no 9394, de 20 de dezembro de 1996. Fixa as Diretrizes e Bases da Educação

Nacional. Disponível em: http://www.portal.mec.gov.br/seesp. Acesso em: abr. 2006.

MEC. Em aberto. Plano Decenal de Educação para Todos. №. 59(especial), ano 13, jul./set. Brasília, 1993.

MEC. Lei de Diretrizes e Bases da Educação Nacional, LDB 9.394 de 20de dezembro de 1996.

MEC/CNE. Diretrizes Nacionais para Educação Especial na Educação Básica. Aprovado em 03 de julho de 2001. Brasília: CEB, 2001.

MANTOAN, Maria Tereza Eglér. Inclusão Escolar: O que é? Por quê? Como Fazer? 2 ed. São Paulo: Moderna, 2006.

RODRIGUES, P.S.S.; OLIVEIRA, G.F. A integração e inclusão do sujeito com deficiência no âmbito social e educacional. Id on Line Revista de Psicologia, Set-Out, vol.10, n.31, Supl 2, p. 54-65, 2016.

<http://gestaoescolar.abril.com.br/politicas-publicas/legislacao-educacional-tratainclusao>- Publicado em Julho 2009. Acesso em 18 de agosto de 2016.

Como citar este artigo (Formato ABNT):

MATOS, M.D. O processo da Inclusão no Ensino Regular. Id on Line Revista Multidisciplinar e de Psicologia, Janeiro de 2017, vol.10, n.34, p. 64-76. ISSN: 1981-1179.

Recebido: 27.01.2017

Aceito: 25.01 .2017 